\title{
Turbidimetric Measurement for On-line Monitoring of $\mathrm{SiO}_{2}$ Particles
}

\author{
In-Sook Kim, Yangsun Kim, ${ }^{\dagger}$ and H. B. Lim ${ }^{\star}$
}

\author{
Department of Chemistry and NSBT, Dankook Lnwersity Youngsan-ku, Hannam-dong, 1ft. 48 , Seoul 140-714, Korea \\ -Proteonik, Inc, Gveonggi Technopark, Rm. 911, 1271-11, Sa-l-dong, Sangnok-gu, Ansan, Kumggi-do +25-170, Korea \\ Received January 8,2004
}

\begin{abstract}
In this work. the fundamental study of on-line monitoring of $\mathrm{SiO}_{2}$ particles in the size range of $40 \mathrm{~nm}$ to 725 nim was carried out using turbidimetry. The size of particle was measured using a field entission scanning electron microscope (FE-SEM). The factors affecting on the turbidity were discussed. for example, wavelength, size, and concentration. In order to observe the dependence of turbidity on the wavelength a turbidimetric system equipped with charged coupled detector (CCD) was built. The shape of the transmitted peak was changed and the peak maximum was shifted to the red when the concentration of particle was increased. This result indicates that the turbidity is related to the wavelength. which corresponds to the characteristic of the Mie extinction coefficient. Q, that is a function of not only particle diameter and refractive index but also wavelength. It is clear that a linear calibration curve for each particle in different size can be obtained at an optimized wavelength.
\end{abstract}

Key Words : Turbidimetry. $\mathrm{SiO}_{2}$ particle. On-line monitoring

\section{Introduction}

$\mathrm{SiO}_{2}$ slurry particles in submicron size are commonly used for chemical mechanical planarization in semiconductor manufacturing process. The size, shape and dispersion of the particles in a strong alkali solution are the important factors to be controlled precisely to increase production yield in the process. On-line particle monitoring becomes important for the fast response and the reduction of production cost. There are various sensitive and effective scattering techniques. such as turbidimetry. nephelometry, and scattering. developed to count the number of particles and obtain the information of particle size distribution. ${ }^{1}$ However. for online monitoring. some limitations still exist such as the requirement of complicated software and heavy instrumental components: for example, a laser for a light source ${ }^{2}$ In this work turbidimetry was employed to monitor the particles by using a compact on-line system.

There were several on-line measurements of solids concentration using turbidimetry: For example, four different samples ( $\mathrm{PVC}$, sand. protein and $\mathrm{KCl}$ ) with solids concentrations up to $10 \mathrm{wt} \%$ were used. ${ }^{3}$ The exact concentration of even very small samples could be determined in a nondestructive way. The capacities and limits of turbidimetry for determining the particle concentration in latexes were studied. tis $^{\text {Not }}$ Nonly the particle concentration but also the specific turbidity of size dependence can be determined. For example. laboratory based studies related to the reflectance response of suspensions carrying different soil types and particle sizes of varying concentrations were reported. ${ }^{6}$ In this case. the reflectance increased with a decrease in the particle size for any soil type. Recently the physical basis of turbidity by light transmission and light scattering is briefly' reviewed. and alternative methods are considered. ${ }^{7}$ These

*Corresponding Author. e-mail: plasmaià dankook-ac.kr include particle counting. which can give detailed information on the number and size of particle and is highly sensitive for particles larger than about $1 \mu \mathrm{m}$. It also should be mentioned that the size at which the maximum occurs depends greatly on the refractive index. ${ }^{8}$ The maximum turbidity is lower for the lower refractive index. For instance, it is not possible to derive information on particle concentration from turbidity measurement unless the nature of the particles is known. The effect of refractive index and particle size on the turbidity was discussed in the paper. but not for the wavelength dependence. The analysis of attractive forces between latex particles by scattering measurements was studied. ${ }^{9.11}$ In addition the potential limits of turbidimetry as a particle sizing method are discussed with respect to several aspects, theoretical. and experimental. ${ }^{11}$

Even with many research reports. wavelength dependence of turbidimetry was rarely reported. It was proposed that turbidimetry at several wavelengths and elastic light scattering at several angles can be used to determine particle size distributions of suspended particles using Mie scattering theory. ${ }^{12}$ Two turbidimeters with a spectral peak response of the detection systems between 400 and $600 \mathrm{~cm}$ have been compared with one that measures scattered light with a wavelength of $860 \pm 10 \mathrm{~nm}^{13}$

Off-line analysis of $\mathrm{SiO}_{2}$ particles for elemental analysis using atomic spectrometry and particle control on the wafer surface in the semiconductor manufacturing process were discussed and previously reported. ${ }^{1+15}$ In this work, the fundamental study on the on-line monitoring of $\mathrm{SiO}_{2}$ particles in the size range of $40 \mathrm{~nm}$ to $725 \mathrm{~nm}$ was carried out using turbidimetry for potential application to semiconductor manufacturing process. Various factors affecting the turbidity, such as wavelength, particle size, and concentration. were studied by monitoring the intensity of the light interacted with the particles. 


\section{Experimental Section}

Instruments. A typical turbidimetric system except a CCD for wavelength study was built and used in this experiment. The system used a tungsten lamp (Osram. 50W. $12 \mathrm{~V}$ ) as a light source and the CCD detection system (KMac. Spectra Vicw 2000. Dacjon. Korea) with a maximum sensitivity between 400 to $800 \mathrm{~nm}$. The quartz. cells. cell path length of $10 \mathrm{~mm}$. and planar convex lenses with a focal length of $50 \mathrm{~mm}$ for collimaled beam were used. A pinhole with $500 \mathrm{~mm}$ diameter was used right before the cell. The transmitted light through the cell was guided into CCD by optical tiber (K-Mac, SPI-1, Dacjon, Korea). The operating condition of $C C D$ was $25 \mathrm{~ms}$ of integration time and 3 times averaging

Chemicals and particles. $\mathrm{SiO}_{2}$ particles in dillerent sizes used were provided by companies and manufacturer (Dupont. Syton HT50 for $40 \mathrm{~nm}$, Starex Co. Starem for $70 \mathrm{~mm}$. l Lannam University. Korea, for $400 \mathrm{~nm} .450 \mathrm{~nm}$. and 725 nn1). Since the sizes of all the particles were uncertain, the particle size was measured using a field emission scanning sectron microscope (FГ-SEM. 10 kV. S-4700. Hiach. Japan) in Korca Basic Science Institute (KBSl) of Chunju. The particles were dispersed using Sodium Phosphate. tribasic (Analytical grade. Duksan. Korea), as a dispersant after sonication for more than $30 \mathrm{~min}$.

\section{Results and Discussion}

Measurement of particle size. Five different sizes of particles less than $1 \mu \mathrm{m}$ were prepared to see the eftect of parlicle size on the turbidity change and wavelenglh dependence. The size of $\mathrm{SiO}_{2}$ particles obtained in this experiment were measured using FE-SFM and the results are shown in Figure 1. As shown in the figures, the particles less than 70 $\mathrm{nm}$ is random in shape whereas the others larger than 400 $\mu \mathrm{m}$ are completely spherical. All the concentrations of the particles were prepared in weight pereent. and the number of particle can be estimated by assuming the particle density of $2.65 \mathrm{~g} / \mathrm{mL}$. As a result. the sizes of particle used in this experiment were $40.2 \mathrm{~nm}( \pm 9.1 \mathrm{~nm}), 69.7 \mathrm{~nm}( \pm 19.5 \mathrm{~mm})$. $403.9 \mathrm{~nm}( \pm 40.4 \mathrm{~nm}) .436 .9 \mathrm{~nm}( \pm 30.5 \mathrm{~nm})$. and $725.3 \mathrm{~nm}$ $( \pm 29.0 \mathrm{~nm})$. The standard deviations were obtained by averaging the sizes of the particles shown in Figure 1. As a result. mono-disperse suspensions can be obtained with the particles used in this experiment.

Fffect of wavelength and concentration on turbidity for particles over $400 \mathrm{~nm}$. Mcasurement of transmittance for a suspension of known particle concentration provides a method to estimate the mean particle size. The transmittance, $T$. of a dilute mono-disperse suspension is given by the Beerl.ambert law as:.

$$
T-\frac{I}{I_{i}}-\exp (-\varepsilon \mathrm{Cl})
$$

where $l_{o}$ is the intensity of the light soure of wavelength $\lambda$. (a) $\mathrm{SiO}_{2} 50.2 \mathrm{~nm}$

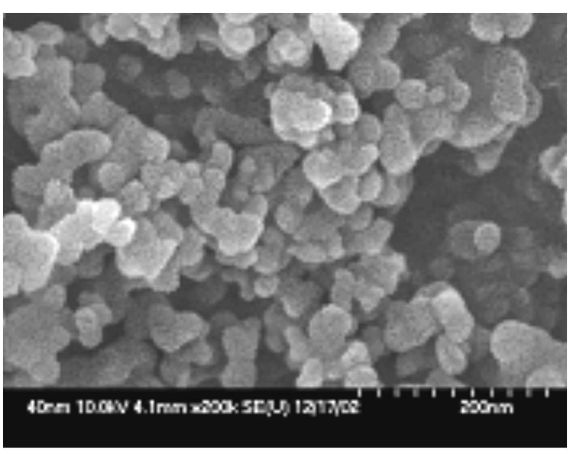

(b) $\mathrm{SiO}_{2} 69.7 \mathrm{~nm}$

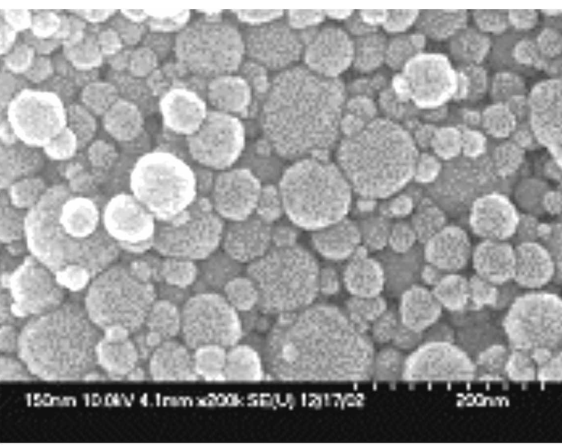

(c) $\mathrm{SiO}_{2} 503.9 \mathrm{~nm}$

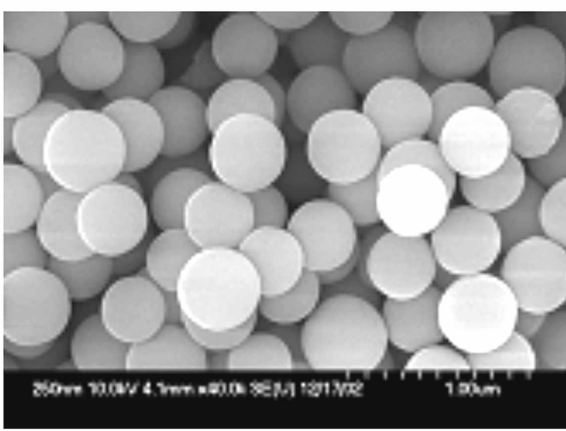

(d) $\mathrm{SiO}_{2} 436.9 \mathrm{~nm}$

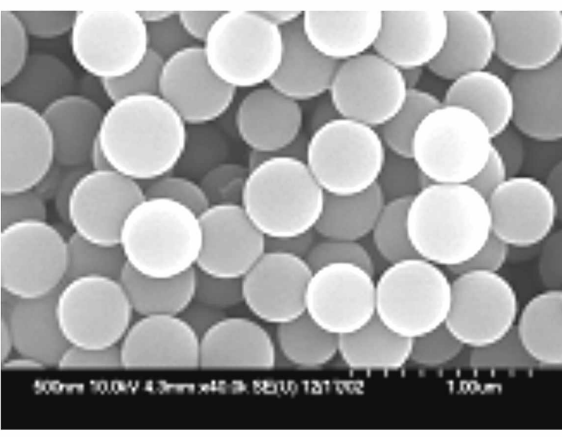

(e) $\mathrm{SiO}_{2} 725.3 \mathrm{~nm}$

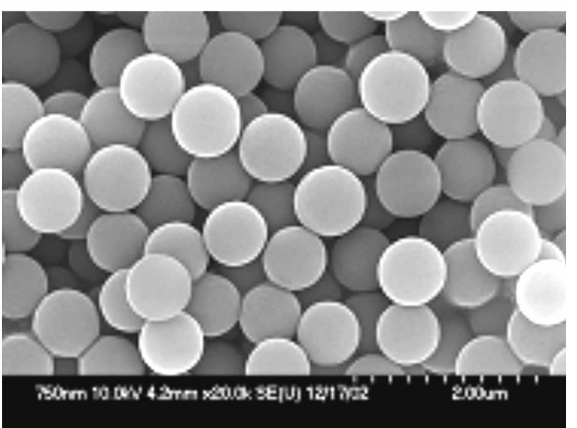

Figure 1. SEM pictures for $\mathrm{SiO}_{2}$ particles using FE-SEM; (a) 40.2 nוm. (b) $69.7 \mathrm{~nm}$. (c) $403.9 \mathrm{~nm}$, (d) $436.9 \mathrm{~nm}$, and (e) $725.3 \mathrm{~nm}$. 


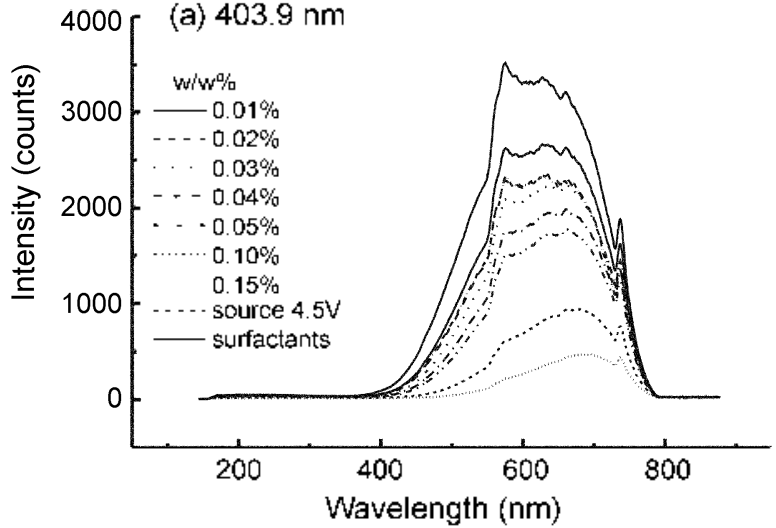

(b) $436.9 \mathrm{~nm}$

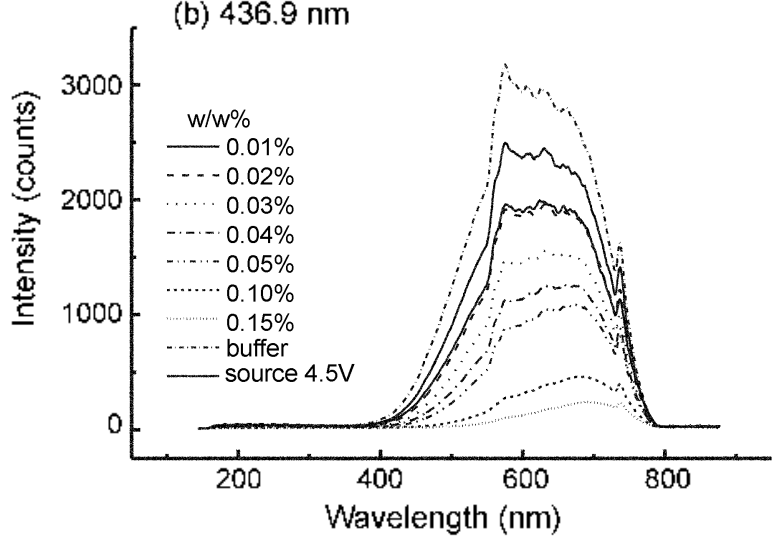

Figure 2. biflect of particle concentration on transmitted intensity obtained in the wavelength range of $400 \mathrm{~nm}$ to $800 \mathrm{~nm}$; (a) for $403.9 \mathrm{~nm}$ and (b) for $436.9 \mathrm{~nm} \mathrm{SiO}$, particles.

$I$ is the intensity of the beam passed through the cell, $\varepsilon$ is the absorption coefficient, $I$ is the cell path length, and $C$ is the concentration per unit volume. For suspensions with high solids concentration and larger particles, the reduction in light intensity, $I$, is related to turbidity $\tau$.

$$
T=\frac{I}{I_{1}}=\exp (-\tau)
$$

If there is a poly-disperse suspension with large particles, it is difficult to relate particle size to turbidity. Instead, turbidity can be estimated from Mie theory;

$$
\tau\left(\lambda_{0}\right)=\frac{\pi}{4} \mathrm{~N} \int_{0}^{\infty} Q\left(\lambda_{i}, D\right) D^{2} f(D) d D
$$

where $O$ is the Mie extinction coefficient. $N$ is the number of particle, and $D$ is the particle diameter. Particles over $400 \mathrm{~mm}$ diameter are in the Mie theory regime.

[n this experiment all the suspensions were prepared to contain high solids concentration with large particles. In order to minimize some forward-scattered light reaching the detector, a collimated beam and a pinhole in front of detector were used. The effect of wavelength and concentration on turbidity for the particles in the size of $403.9 \mathrm{~nm}( \pm 40.4 \mathrm{~nm})$, $436.9 \mathrm{~nm}( \pm 30.5 \mathrm{~nm})$, and $725.3 \mathrm{~nm}(=29.0 \mathrm{~nm})$ were studied and the results for $403.9 \mathrm{~mm}$ and $436.9 \mathrm{~nm}$ are shown in Figure 2 and 3 . The similar result for the particle size of
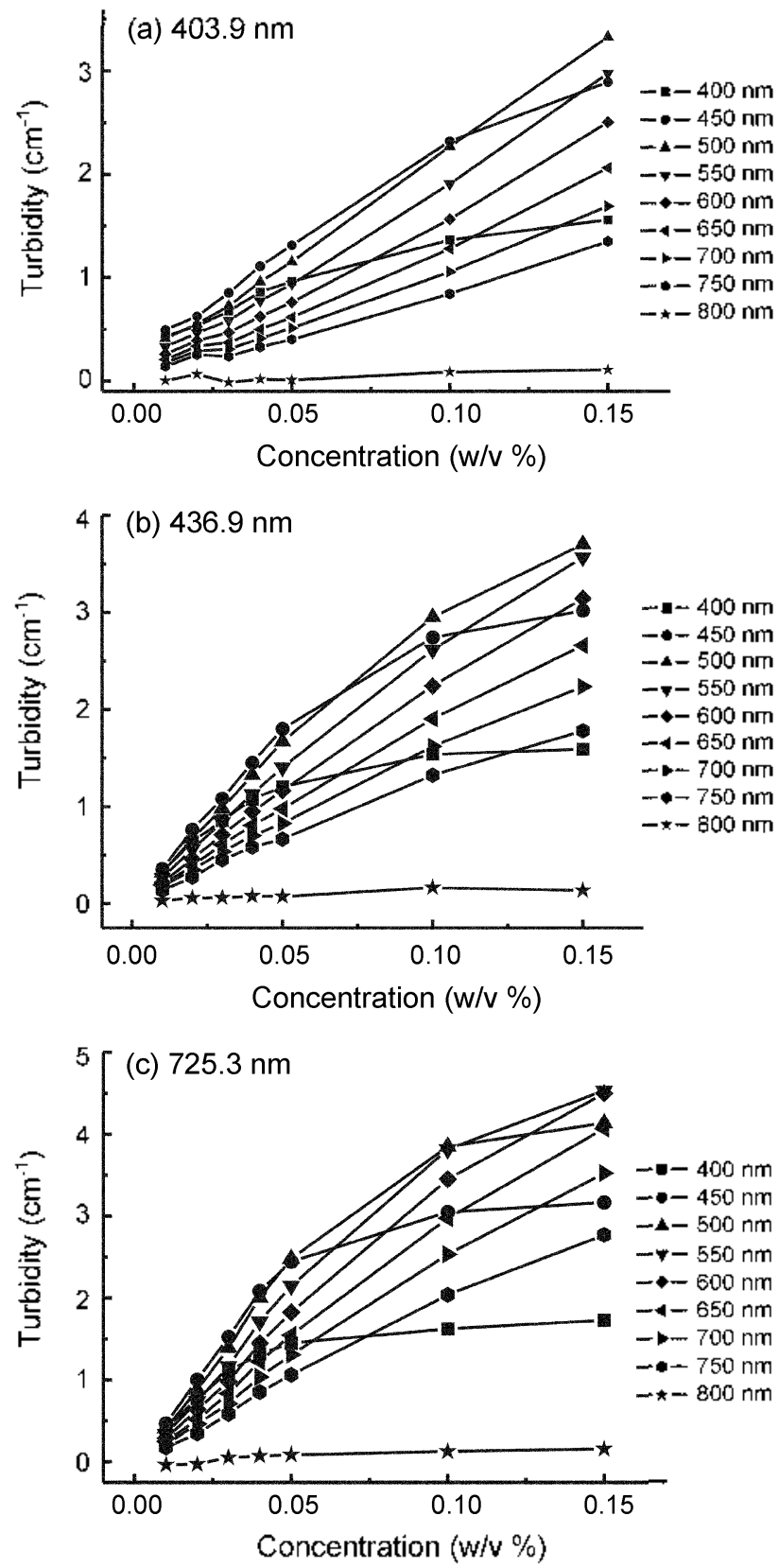

Figure 3. Relationship between turbidity and concentration of (a) $403.9 \mathrm{~nm}$. (b) $436.9 \mathrm{~nm}$. (c) $725.3 \mathrm{~nm} \mathrm{SiO} 2$ particle in the wavelength range of $400 \mathrm{~m}$ to $800 \mathrm{~nm}$.

$725.3 \mathrm{~nm}$ was observed. As shown in Figure 2, the shape of the transmitted peaks was changed and the peak maximum was shifted to the red when the concentration of particle was increased. This result indicates that the turbidity is related to the wavelength, which corresponds to the characteristic of the Mie extinction coefficient $Q$ that is a function of not only particle diameter and refractive index but also wavelength. The plot of concentration vs. turbidity was shown in tigure 3. Linear relationships for $403.9 \mathrm{~nm}$ particle were obtained in the wide range of wavelengths, i.e., from $500 \mathrm{~nm}$ to 750 $\mathrm{nm}$. But, the linearity became worse as the particle size increased, i.e., the linear relationships were obtained in the narrower wavelength range. The reason for the wavelength 


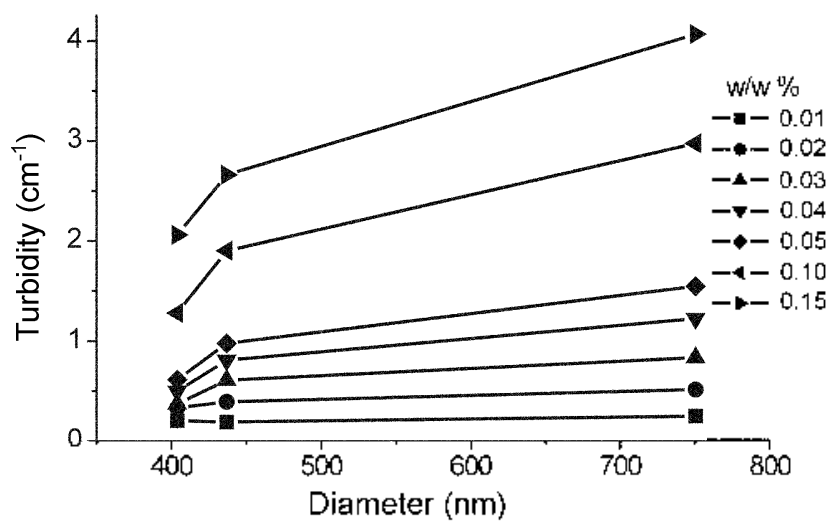

Figure 4. Lffect of particle size on turbidity for $\mathrm{SiO}_{2}$ particle.

dependence of the turbidity was unclear at this moment, but expectedly the particle size and/or the wavelength might be one of the parameters affecting the Mie extinction coefficient and the turbidity. It is certain that, from the figure, the concentration of particle can be estimated if the suspension is mono-dispersed.

As the diameter of the particle increased at a certain concentration, the turbidity increased although the increment was not linear, and the result is shown in Figure 4. As the concentration increased, the curve became deviated negatively from the linearity. The reason is that the concentration was calculated not the number of particles but weight percent.

From these results it can be concluded that Mie scattering theory can be used for the particles used in this experiment. Also, the optimum condition to estimate the number of particles in the mono-dispersed suspension was studied and the variable factors were not only particle size but also wavelength. Fspecially the wavelength dependence of the turbidity was clearly shown in this experiment.

Effect of wavelength and concentration on turbidity for particles below $70 \mathrm{~nm}$. For smaller particles less than the wavelength $\lambda_{0}$ of light source $\left(D / \lambda_{0}<0,1\right)$ or when the refractive index of the particles is very close to that of the medium, the scattering effect becomes more significant. ${ }^{3}$ In this case, the Rayleigh theory applies for the scattering. A steep reduction in scattered light is expected as the particle size decreases, so that suspensions of very small particles appeared almost transparent. Also, light scattering increases strongly as the wavelength decreases and it leads to an angular distribution of scattered light and a reduction of transmitted light. In this experiment, the particles of $40.2 \mathrm{~mm}$ and $69.7 \mathrm{~nm}$ are small compared to the wavelength and theoretically in the boundary between the Rayleigh and Mie theory.

The transmitted spectra for the mean particle size of 40.2 $\mathrm{nm}$ and $69.7 \mathrm{~nm}$ are shown in Figure 5 . From the figure it was observed that the shape of the peak was changed and the peak maximum was shifted to red, similar to that for the particles larger than $400 \mathrm{~nm}$. It indicates that the turbidity is still related to the wavelength and the characteristic of Mie scattering. The transmitted light intensity, I, was significantly decreased. compared to that for the particles larger than 400
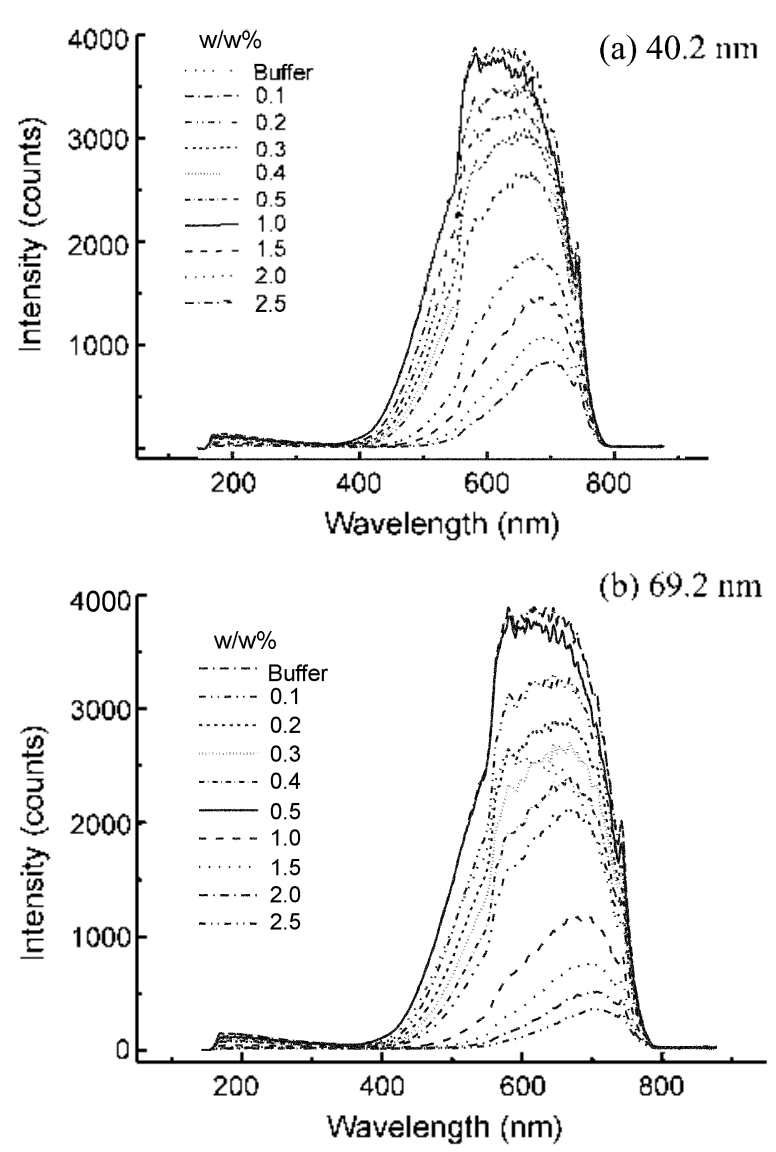

Figure 5. Filject of particle concentration on transmitled intensity oblained in the wavelength range of $400 \mathrm{~nm}$ to $800 \mathrm{~nm}$; (a) for 40.2 nm and (b) for $69.7 \mathrm{~nm} \mathrm{SiO}_{2}$ particles.

nin. It means that, if the particle size were smaller than the wavelength, light scattering was strongly decreased and the suspension became inore transparent.

Figure 6, obtained from Figure 5, shows the plot of concentration vs. turbidity at different wavelengths. The slope difference between $40.2 \mathrm{~nm}$ and $69.7 \mathrm{~nm}$ indicates the particle size effect on the turbidity. The slope of $40.2 \mathrm{~nm}$ particles is larger than that of $69.7 \mathrm{~nm}$ particles. This trend was different from that for the larger particles described in Figure 3 . The reason is unclear, but the relationship between particle size and wavelength probably resulted in the trend because the particles of $40.2 \mathrm{~nm}$ and $69.7 \mathrm{~nm}$ are small compared to the wavelength. It is clear that a linear calibration curve can still be obtained at an optimized wavelength for each particle size. For instance, a linear calibration curve was obtained at the wavelength of $550 \mathrm{~nm}$ and $600 \mathrm{~nm}$ for 40.2 and $69.7 \mathrm{~nm}$ particles, respectively.

Similarly, it is known that the maximum turbidity is lower for the lower refractive index. ${ }^{8}$ Therefore, it is not possible to derive information on particle concentration from turbidity measurement unless the nature of particles is known. In this experiment, the refractive index of the particles was not considered because the particles were pure $\mathrm{SiO}_{2}$ used in semiconductor manufacturing process with a known refractive index. 

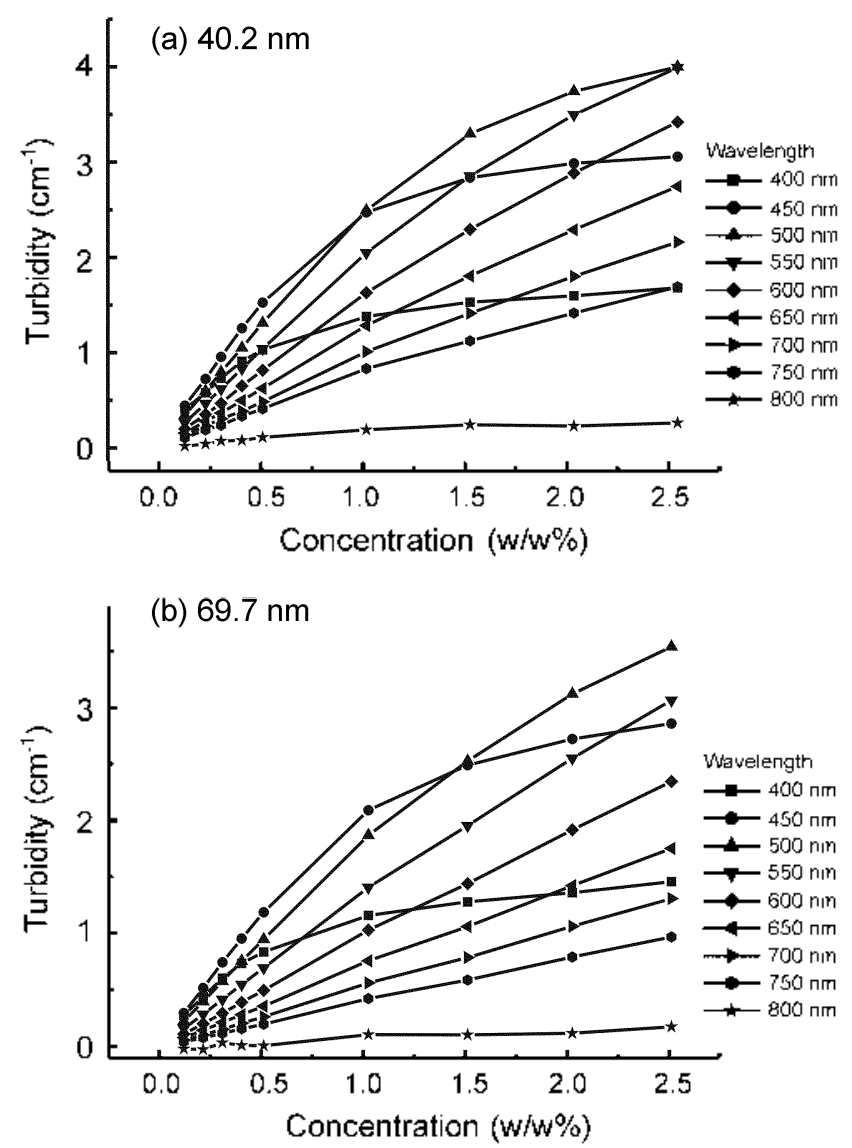

Figure 6. Relationship between turbidity and concentration in the wavelength range of $400 \mathrm{~nm}$ to $800 \mathrm{~nm}$; (a) for $40.2 \mathrm{~nm}$ and (b) for $69.7 \mathrm{~nm} \mathrm{SiO}$, particle.

In conclusion, although the reason is unclear, the particle size and the wavelength may affect the turbidity and the linearity of calibration curve. Based on this experimental result, it turned out that the on-line monitoring of the particle might be possible by optimizing the operating parameters such as the wavelength, the particle size, and the concentration.

Acknowledgements. The authors would like to thank Prof. Jongsung Ryu, Hannam University, and Dr. H. S. I.ee of KBRl for their supports. This work was supported by Grant 1999-2-124-001-5 of the Interdisciplinary Research Program, KOSГF.

\section{References}

1. Matukail. S.: Ben-Tyur. Y: Rebhun. M. Hater Science and Techology 1997. 36(4), 225 .

2. Volten. H.: De Haan. J. F.: Vassen. W.: Lumme. K.: Hovenier. J. W. J. terosol Sci. 1996. 27. 5527.

3. Raphacl. M.: Rohani. S. Powder Technolog 1996. 89.157.

4. Irache J. M.: Durrer. (.: Ponchel. Gi.: Duchene. D. Internationat Joufnal of Phembacentics 1993.90(3). R9.

5. Ilarris (i. W. Pouder Techrology 1970. 3(1), 107.

6. Bhargava. D. S.: Marian. D. W. ISPRS Jommal of Photogrammetny and Remote Sernsing 1991. $\neq 6(4) .217$.

7. Gregory. J. Filtration \& Sepuration 1998. Jun Teh. 63.

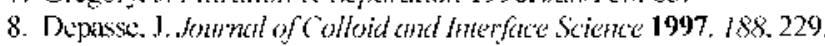

9. Weiss, A.: Horner. K. 1).: Ballauft. M. Jownat of Collodd and Interfoce Science 1999. 2/3.417.

10. Gossen. 1'. D.: MacGreger. I. F. Jommat of Colloid and hiterface Sistence 1993. $160(1) .24$.

11. Craw ley. G.: Courni. M.: Di Bencdetto. D. Powder Fechnolog' 1997.91 .197

12. Fidicabe. (3.. Frontini. (3. Jommal of Colloid and Imerface Sciefree 1996. 181.669

13. Hongve. D.: Akesson. (i. Wat. Res. 1998. 32(10). 3143.

14. Lim. H. B.: Kim. T. H.: Eom. S. H.: Sung. Y.-j.: Moon. M. H.: Lec. D. W. J. Anat Ato. Spectrom. 2002. 17. 109.

15. Jum, P. K.: I.jm. II. B. J. Anchl. At. Spectrom. 2003. $/ 8 . \mathrm{III}$. 